\title{
FUNGAL MICROBIOTA FROM OCULAR CONJUCTIVA OF CLINICALLY HEALTHY HORSES BELONGING TO THE MILITARY POLICE CAVALRY OF ALAGOAS.
}

\author{
Maria Evódia de Sousa ${ }^{1 *}$, Maria Anilda dos Santos Araújo², Rinaldo Aparecido Mota ${ }^{3}$, Wagnner José Nascimento Porto ${ }^{3}$, \\ Aryanna Kelly Pinheiro Souza ${ }^{4}$, Josimeire Lima dos Santos², Patrícia Paes da Silva² \\ ${ }^{1}$ Universidade Federal Rural de Pernambuco, Ciência Veterinária, Recife, PE, Brasil; ${ }^{2}$ Fundação Educacional Jayme de Altavila, \\ Faculdade de Ciências Biológicas e da Saúde, Centro de Estudos Superiores de Maceió, Maceió, AL, Brasil; ${ }^{3}$ Departamento de \\ Medicina Veterinária, Universidade Federal Rural de Pernambuco, Recife, PE, Brasil; ${ }^{4}$ Ciências da Saúde, Instituto de Ciências \\ Biológicas e da Saúde, Universidade Federal de Alagoas, Maceió, AL, Brasil.
}

Submitted: November 09, 2009; Approved: March 14, 2011.

\begin{abstract}
Normal fungal conjunctiva microbiota of horses remains stable in healthy animals, free from ocular and/or systemic diseases which may, eventually, cause ocular alterations. The knowledge of the fungal microbiota is of great importance due to the reduced number of studies reported in the literature and also to the large occurrence of ocular alterations, mainly keratomycosis, in these animals. The aim of this study was to isolate and to identify the fungi present in the ocular conjunctiva of healthy horses belonging to the Military Police Cavalry of Alagoas. Samples from both conjunctival sacks from 50 horses were taken using a sterile swab and submitted to fungal cultures. These samples were seeded by radial spreading of the swabs on the Sabouraud agar surface with chloramphenicol, at a concentration of 50mg/L, in Petri dishes. Next, dishes were incubated at room temperature $\left( \pm 28^{\circ} \mathrm{C}\right)$ for 15 days. Horses conjunctival fungal microbiota was found to be composed by Aspergillus spp. (62\%), Microsporum gypseum (6\%), Penicillium spp. (6\%), Curvularia spp. (5\%), Candida spp. (3\%), Fusarium spp. (3\%), Acremonium spp. (2\%), Bipolaris sp. (1\%), Cladosporium sp. (1\%), Chrysosporium sp. (1\%), Rhodotorula sp. (1\%), Aureobasidium sp. (1\%) and Scopulariopsis sp. (1\%). There is a wide variety of yeast-like and filamentous fungi colonizing the clinically healthy horses' ocular conjunctiva, out of which Aspergillus sp. is predominant. Although this was a straightforward study and have not recorded any ocular lesions that suggest fungi infections, these fungi might eventually be involved in this type of ocular pathology for the studied species.
\end{abstract}

Key words: microbiota, fungi, horses, ocular conjunctiva

\section{INTRODUCTION}

The conjunctiva is a fine, transparent membrane through which the sclera and the subconjunctival tissues are clearly visible (19). The conjunctiva can be divided into palpebral and bulbar conjunctiva, and the fornix is the junction among them, where a structure similar to a sac bottom is formed (14). It covers the internal surface of the palpebral conjunctiva, reflects

*Corresponding Author. Mailing address: Med. Vet., curso de Pós-Graduação - UFRPE - Ciência Veterinária.; Cel.: (82) 9925-8925.; E-mail: evodia.sousa@hotmail.com 
in the superior and inferior conjunctiva fornices by covering the sclera up to the limbus, also covering the anterior and posterior surfaces of the third eyelid (12). This membrane is continually exposed to infectious agents such as virus, bacteria and fungi; hence, the conjunctiva sac is not, indeed, sterile (19).

The conjunctiva and the cornea have a strong defense system against fungal infections. This system is made up of immunological, metabolic and antimicrobial mechanisms, and of a physical tissue barrier (16). Included into these mechanisms are: the ongoing tear flow, phagocytic actions, mechanical barriers and the lysozyme bacteriostatic action. An imbalance of any of these factors can expose the eye to a possible infection by either endogenous or exogenous pathogens (3).

According to Pentlarge (12), amongst the imbalances that could expose the eye to an infection are stress, impaired immunological state, lack of the lachrymal pellicle, systemic diseases, traumatism and abnormal conformation of the eyelids, such as lagophthalmia and exophthalmia, situations that potentiate the exposure and the dryness of the conjunctiva.

Among these ophthalmic alterations that assault horses, keratomycosis is an important disease that has been often diagnosed (17). This disease may occur in a deceitfully form with a long lasting period of treatment, resulting in an extensive fibrovascular cicatrization of the cornea (1).

In Brazil there are no available data on the prevalence of keratomycosis in equines, however it does occur and is common, mainly due to the humid and hot climatic conditions which favors these infections $(6,9)$.

The aim of this study was to isolate and to identify the fungi present on the ocular conjunctiva of clinically healthy horses maintained at the Military Police Cavalry of Alagoas.

\section{MATERIAL AND METHODS}

This study was carried out during April and May, 2007, at the the Military Police Cavalry of Alagoas, located in
Bebedouro, a district of Maceió, AL.

Samples were collected from 50 horses (a total of 100 samples) which did not show any ocular disease and/or any systemic alteration that could eventually initiate an ocular modification. Animals used were from different sexes, breeds and ages (2-26 years old).

After animals' physical restraint, samples were collected from both conjunctival sacs by using a dry sterilized swab for each eye. The swab was gently positioned against the eye and carefully rotated in order to make no contact with the animal skin and eyelids. Immediately after the collection, the swabs were placed into test tubes containing distilled water with antibiotic (chloramphenicol, 50mg/L), properly labeled and taken to the Fungi Laboratory of the Biological and Health Sciences College of CESMAC (Centro de Estudos Superiores de Maceió) for further analyses.

The samples were seeded by radially spreading the swabs on the surface of the Sabouraud agar with chloramphenicol at a concentration of $50 \mathrm{mg} / \mathrm{L}$ in Petri dishes. The plates were carefully labeled and incubated at room temperature $\left( \pm 28^{\circ} \mathrm{C}\right)$ for 15 days.

Three days after incubation, colony counts (ColonyForming Units, CFU) were obtained from both eyes of each animal, along with the differential colony counts between filamentous and yeast-like fungus colonies. The species were qualitatively divided into genus and species of the isolated fungi.

Each colony was incubated in three test tubes containing Sabouraud agar with cloramphenicol $(50 \mathrm{mg} / \mathrm{L})$, and maintained at room temperature $\left( \pm 28^{\circ} \mathrm{C}\right)$ for 7 days for further identification.

Identification of the isolated filamentous and yeasts fungi was carried out by the colonies macro and micro morphological characteristics, according to the criteria used by Otcenasek and Dvorack (11), Rebell and Tapplin (15), Hoog et al. (7) and Lacaz et al. (8).

After identification, fungi were kept in tubes containing distilled water and sterilized mineral oil. 


\section{RESULTS AND DISCUSSION}

Out of the 100 analyzed samples, $73(73 \%)$ were positive. The majority of the fungi isolated were from the genus Aspergillus spp. (55\%), followed by Aspergillus fumigatus (7\%), Penicillium spp. (6\%), Microsporum gypseum (6\%),
Curvularia spp. (5\%), Candida spp. (3\%), Fusarium spp. (3\%), Acremonium spp. (2\%), Aureobasidium sp. (1\%), Bipolaris sp. (1\%), Chrysosporium sp. (1\%), Cladosporium sp. (1\%), Rhodotorula sp. (1\%), Scopulariopsis sp. (1\%) and unidentified fungus due to the lack of reproductive structures $(9 \%)$ (Table 1).

Table 1. Fungi isolated from conjunctival sacs of horses kept at the Military Police Cavalry of Alagoas, Maceió, 2007.

\begin{tabular}{lc}
\hline \multicolumn{1}{c}{ Fungi } & Conjunctival sacs (samples) \\
\hline Acremonium spp. & 2 \\
Aspergillus spp. & 55 \\
Aspergillus fumigatus & 7 \\
Aureobasidium sp. & 1 \\
Bipolaris sp. & 1 \\
Candida spp. & 3 \\
Chrysosporium sp. & 1 \\
Cladosporium sp. & 1 \\
Curvularia spp. & 5 \\
Fusarium spp. & 3 \\
Microsporum gypseum & 6 \\
Penicillium spp. & 6 \\
Rhodotorula sp. & 1 \\
Scopulariopsis sp. & 1 \\
\hline Total & 93 \\
\hline
\end{tabular}

Amongst the negative samples, ten were negative for both eyes, 12 were negative only for the right eye and five were negative only for the left eye.

From the 73 positive samples, 56 were positive for both eyes, 12 were positive only for the left eye and five only for the right eye.

Regarding the pure or associated isolation, 25 samples $(34.24 \%)$ showed associated isolation of fungi, $46(63.01 \%)$ showed isolation in pure culture and two samples were contaminated. The associations isolated with greater frequency were Aspergillus spp. + Microsporum gypseum (16\%), Aspergillus spp. + Aspergillus fumigatus (12\%), Aspergillus spp. + Penicillium spp. (12\%), Aspergillus spp. + Candida spp. (8\%), Aspergillus spp. + unidentified fungus (8\%) and other associations (4\%) (Table 2).

The results of this study are in accordance with several other studies $(17,20,10,16)$ in which Aspergillus genus was referred to as being predominant in the fungal microbiota of clinically healthy horses' conjunctiva. This genus is widespreaded, particularly in vegetables, and their conidium are found on the surface of grains and, consequently, in rations. It is the most important genus in Veterinary Medicine, and may be responsible for numerous pathological processes. All animals, including man, are susceptible to infections caused by Aspergillus sp. (4).

A different result was observed in São Paulo, in a study of normal microbiota of horses conjunctiva under different management conditions, where Candida sp. (13) was the predominant genus.

Keratomycosis is an infection of the cornea caused by fungi proceeding from the conjunctival microflora or the surrounding atmosphere, introduced into the corneal stroma, 
after trauma or pre-existent bacterial infection (1). According to Pisani et al. (13), these fungi vary according to the geographic region and season of the year, with prevalence during the summer. Aspergillus sp., Cladosporium sp., Alternaria sp. and Penicillium sp. are predominant in most of the studies on conjunctival and cornea microbiota of horses. Fusarium sp. and yeast could also be commonly isolated in some regions $(17,20,10)$. Among the animal species, horses are more susceptible due to factors such as a high concentration of fungi in the environment where they live in and also in the conjunctival sac of healthy animals. Hence, the frequent accidental introduction of vegetal material contaminated with fungus into the ocular region, as well as the indiscriminate use of topic corticosteroids in ocular affections are occurrences which favor the development of mycotic keratitis in these animals (2).

M. gypseum also recovered in this study is a common soil fungus which, probably, is the most likely source of the infection. Apart from being a fungus generally associated to clinical alterations in humans, it could also be found in horses, dogs, cats, rodents, cattle and wild animals, presenting low incidence and pathogenicity $(5,18)$. This is in accordance with the results found in the present study, since the number of samples from which this fungus was isolated was low and the animals did not present any ocular or systemic alterations.

The knowledge of the fungi present in the ocular conjunctiva of healthy horses is of great importance since it provides subsidies to treat better and more efficiently the ocular affections, mainly keratomycosis, which is very common in these animals.

Table 2. Absolute and relative frequency of microorganisms associations isolated from conjunctival sacs of horses kept at the Military Police Cavalry of Alagoas, Maceió, 2007.

\begin{tabular}{lcc}
\hline \multicolumn{1}{c}{ Microorganisms } & AF (samples) & RF (\%) \\
\hline Aspergillus spp. + Aspergillus fumigatus & 3 & 12 \\
Aspergillus spp. + Acremonium spp. & 1 & 4 \\
Aspergillus spp. + Candida spp. & 2 & 8 \\
Aspergillus spp. + Microsporum gypseum & 4 & 16 \\
Aspergillus spp. + Chrysosporium sp & 1 & 4 \\
Aspergillus spp. + Penicillium spp. & 3 & 12 \\
Aspergillus spp. + Fusarium spp. & 1 & 4 \\
Aspergillus spp. + Rhodotorula sp & 1 & 4 \\
Aspergillus spp. + fungi not identified & 2 & 8 \\
Aspergillus spp. + Acremonium spp. + Curvularia spp. & 1 & 4 \\
Aspergillus spp. + Fusarium sp + fungi not identified & 1 & 4 \\
Aspergillus spp. + Bipolaris sp + Curvularia spp. + Scopulariopsis sp & 1 & 4 \\
Aspergillus spp. + A. fumigatus + Candida spp. + Curvularia spp. & 1 & 4 \\
A. fumigatus + Aureobasidium sp & 1 & 4 \\
Fusarium spp. + fungi not identified & 1 & 4 \\
Penicillium spp. + fungi not identified & 1 & 4 \\
\hline Total & 25 & 100 \\
\hline
\end{tabular}

\section{CONCLUSION}

The results of this study allow us to conclude that there is a great variety of filamentous and yeast-like fungi colonizing the ocular conjunctiva of clinically healthy horses, predominantly characterized by Aspergillus sp. Although this was a straightforward study and there was a lack of observation of ocular lesions suggesting fungal infections, these fungi might eventually be involved in the ocular pathologies of this species. 


\section{REFERENCES}

1. Andrew, S.E.; Brooks, D.E.; Smith, P.J.; Gelatt, K.N.; Chmielewski, N.T.; Whittaker, C.J.G. (1998). Equine ulcerative keratomicosis: visual outcome and ocular survival in 39 cases (1987-1996). Equine Vet. J., London, 30 (2), 109-116.

2. Barton, M.H. (1992). Equine keratomicosis. Compendium on Continuing Education for the Practicing Veterinarian, Princeton, 14, 936-944.

3. Bistner, S.I.; Roberts, S.R.; Anderson, R.P. (1969). Conjunctival bacteria: clinical appearances can be deceiving. Mod. Vet. Pract., Goleta, 50 (12), 45-7.

4. Cruz, L.C.H. (1985). Micologia veterinária: estudo e ensino, Rio de Janeiro: Universidade Federal do Rio de Janeiro, 202 p.

5. Cutsem, J.V.; Rochette, F. (1991). Mycoses in domestic animals. [S. 1.]: Janssen Research Foundation, 45-153.

6. Grahn, B.; Wolfer, J.; Keller, C.; Wilcock, B. (1993). Equine keratomicosis: Clinical and laboratory findings in 23 cases. Progress in Veterinary and Comparative Ophthalmology, local, 3, 99-103.

7. Hoog, G.S.; Guarro, J.; Gené, J.; Figueras, M.J. (2000). Atlas of clinical fungi. local: CBS: $1126 \mathrm{p}$.

8. Lacaz, C.S.; Porto, E.; Martins, J.E.C.; Heins-Vaccari, E.M.; Melo, N.T. (2002). Tratado de micologia médica Lacaz. 9. ed. São Paulo: Sarvier, $1104 \mathrm{p}$.

9. Machado, M.L.S.; Oliveira, L.O.; Beck, C.A.C.; Conceição, M.S.N.; Ferreiro, L.; Driemeier, D. (2005). Ceratomicose eqüina causada por Aspergillus flavus. Acta Scientiae Veterinariae, Porto Alegre, 33 (2), 219-223.

10. Moore, C.P.; Heller, N.; Majors, L.; Whitley, R.D.; Burgess, E.C.; Weber, J. (1988). Prevalence of ocular microorganisms in hospitalized and stabled horses. Am. J. Vet. Res., Chicago, 49 (6), 773-777.

11. Otcenasek, M.; Dvorack, J. (1973). Pictorial dictionary of madecal mycology. The Hague: W. Junk, 229 p.

12. Pentlarge, V.W. (1996). Doenças oftálmicas externas e glaucoma In: Lorenz, M.D.; Cornelius, L.M.; Ferguson, D.C. Terapêutica clínica em pequenos animais. local: Iterlivros, cap 14, p. 287-337.

13. Pisani, E.H.R.; Barros, P.S.M.; Ávila, F.A. (1997). Microbiota conjuntival normal de eqüinos. Brazilian Jounal Veterinary Research Animal Science, São Paulo, 34 (5), 261-265.

14. Ranzani, J.J.T. (2000). Anatomia e fisiologia oculares. In: CONGRESSO BRASILEIRO DE CIRURGIA E ANESTESIOLOGIA VETERINÁRIA. 4., 2000, Botucatu. Anais... São Paulo: UNESP.

15. Rebell, G.; Tapplin, D. (1974). Dermatophytes: their recongnition and identification. Miami: Revised, 124 p.

16. Rosa, M.; Cardozo, L.M.; Pereira, J. S.; Brooks, D.E.; Martins, A.L.B.; Florido, P.S.S.; Stussi, J.S.P. (2003). Fungal flora of normal eyes of healthy horses from the State of Rio de Janeiro, Brazil. Veterinary Ophthalmology, Philadelphia, 6 (1), 51-55.

17. Samuelson, D.A.; Andresen, T.L.; Gwin, R.M. (1984). Conjunctival fungal flora in horses, cattle, dogs, and cats. J. Am. Vet. Med. Assoc., Schaumburg, 184 (10), 1240-1242.

18. Sidrim, J.J.C.; Moreira, J.L.B. (2004). Fundamentos clínicos e laboratoriais de micologia médica, Rio de Janeiro, Guanabara Koogan.

19. Stades, F.C.; Boevé, M.H.; Neumann, W.; Wyman, M. (1999). Conjuntiva. In: _ _ Fundamentos de oftalmología veterinária. São Paulo: Manole, 204 p.

20. Whitley, R.D.; Moore C.P. (1984). Microbiology of the equine eye in health and disease. Veterinary Clinics of North America: small animal practice 1984, Philadelphia, 6 (3), 451-466. 